\title{
Correction to: Predicting the clinical trajectory in critically ill patients with sepsis: a cohort study
}

Peter M. C. Klein Klouwenberg ${ }^{1 *}$, Cristian Spitoni ${ }^{2}$, Tom van der Poll ${ }^{3}$, Marc J. Bonten ${ }^{4,5}$, Olaf L. Cremer ${ }^{6}$ and on behalf of the MARS consortium

\section{Correction to: Crit Care (2019) 23:408 https://doi.org/10.1186/s13054-019-2687-z}

In the publication of this article [1], there are 4 collaborating authors missing from the 'MARS consortium'. This has now been included in this correction article.

Marcus J. Schultz Department of Intensive Care, Academic Medical Center Amsterdam, the Netherlands

Janneke Horn Department of Intensive Care, Academic Medical Center Amsterdam, the Netherlands

Brendon Scicluna Center for Experimental and Molecular Medicine, Academic Medical Center Amsterdam, the Netherlands

Maryse A. Wiewel Center for Experimental and Molecular Medicine, Academic Medical Center Amsterdam, the Netherlands

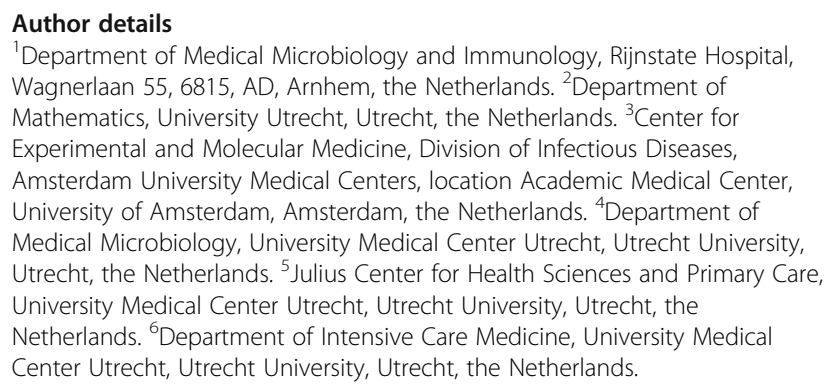

Published online: 06 February 2020

\section{Reference}

1. Klein Klouwenberg PMC, Spitoni C, van der Poll T, et al. Predicting the clinical trajectory in critically ill patients with sepsis: a cohort study. Crit Care. 2019;23:408 https://doi.org/10.1186/s13054-019-2687-z.

\footnotetext{
* Correspondence: peterkk@live.com

The original article can be found online at https://doi.org/10.1186/s13054019-2687-z

${ }^{1}$ Department of Medical Microbiology and Immunology, Rijnstate Hospital, Wagnerlaan 55, 6815, AD, Arnhem, the Netherlands

Full list of author information is available at the end of the article
}

(c) The Author(s). 2020 Open Access This article is distributed under the terms of the Creative Commons Attribution 4.0 International License (http://creativecommons.org/licenses/by/4.0/), which permits unrestricted use, distribution, and reproduction in any medium, provided you give appropriate credit to the original author(s) and the source, provide a link to the Creative Commons license, and indicate if changes were made. The Creative Commons Public Domain Dedication waiver (http://creativecommons.org/publicdomain/zero/1.0/) applies to the data made available in this article, unless otherwise stated. 